Research Article

\title{
Social Service Model and Value Evaluation of Libraries under Sharing Economy
}

\author{
Ping Liu $(\mathbb{D}$, Lijing Cai, and Liqin Luo \\ Hebei University of Science and Technology Library, Shijiazhuang 050018, China \\ Correspondence should be addressed to Ping Liu; liupinglib@hebust.edu.cn
}

Received 25 June 2021; Revised 29 July 2021; Accepted 3 August 2021; Published 3 September 2021

Academic Editor: Daqing Gong

Copyright (c) 2021 Ping Liu et al. This is an open access article distributed under the Creative Commons Attribution License, which permits unrestricted use, distribution, and reproduction in any medium, provided the original work is properly cited.

\begin{abstract}
Libraries are increasingly marginalized by the information construction of electronic resources retrieval platform. This calls for a novel social service model (SSM) for libraries to enhance the overall value of their various service functions. Therefore, this paper explores the SSM and value evaluation of libraries under sharing economy. Firstly, the SSM of libraries was broken down into a base layer, a physical layer, and a virtual layer, and an evaluation index system (EIS) was constructed for the social sharing service (SSS) value of libraries. Next, the SSS value of libraries was evaluated and predicted, and the functional value of the SSM of libraries was analyzed in detail. The proposed prediction model was proved effective through experiments, and the SSS functions of libraries were valued.
\end{abstract}

\section{Introduction}

Libraries in China are undergoing the transform from traditional libraries and digital libraries to composite libraries, while facing the challenges of technology, operations, and popularization [1-6]. With the advancement of society, the users of libraries have expanded from students, teachers, and researchers to the public [7-9]. Unfortunately, libraries are increasingly marginalized by the information construction of electronic resources retrieval platform. This calls for a novel social service model (SSM) for libraries to coordinate their operations and enhance the overall value of their various service functions.

Using the evaluation tool of Insync Surveys, Wu et al. [10] fully considered the convenience, fairness, and public welfare of public libraries and constructed an evaluation index system (EIS) for the service quality of public libraries, which contains 28 secondary indices and 4 primary indices. Community public libraries are the basic unit that provides cultural service to the grassroots. Their development involves numerous factors [11-13]. To complement government fiscal investment, Siregar and Dewiyana [14] optimized the public cultural service system, built up a public-private partnership (PPP) service supply model for libraries, and analyzed the intrinsic logic of introducing the model. After in-depth discussion on the basic attributes of national libraries, Handoko and Girsang [15] determined the rights and obligations between the government, libraries, and enterprises, systematically sorted out the public cultural service responsibilities of libraries, and evaluated the possible operating risks. Through case analysis and questionnaire survey, Singh et al. [16] assessed the information level of college libraries from the angles of physical supporting electronic resources, the number of electronic journals databases, and the level of management platform construction.

Public libraries provide public welfare services, which vary from region to region [17-20]. Based on the theories of public products and fairness, Karna et al. [21] quantified and empirically analyzed problems like the supply equalization of public libraries and formulated a solution from both input and output. To provide the public with rich cultural services, it is necessary to realize innovative development and transform of digital cultural services for public libraries [22-25]. Kourai and Sannomiya [26] summarized the connotations, features, forms, and service states of digital cultural services, defined several evaluation bases for the digital cultural service utility of public libraries, namely, the 
full coverage of disciplines, content innovation, facility intelligence, and activity diversity, and specified the idea of setting up the corresponding EIS. Soares-Silva et al. [27] analyzed the factors affecting the knowledge service performance of public libraries from six aspects: personnel, funds, facilities, resources, activities, and effects.

In the context of open access, innovative service models, which emerged in libraries in North America and Europe, have developed gradually, and the library community in China also paid a high attention to information sharing spaces. At present, information sharing, as a support environment, is the mainstream innovative service model of libraries in the digital age. After reviewing the domestic and foreign literature on library service models, it can be inferred that both library service model and management strategy originate in the West. By contrast, China faces prominent defects in the development and application of library SSM. In fact, the evaluation of service model value has just started in China. No scholar has attempted to apply the management idea of sharing economy to library SSM. Therefore, this paper explores the SSM and value evaluation of libraries under sharing economy. Section 2 details the library SSS, which includes a base layer, a physical layer, and a virtual layer. Section 3 sets up an EIS for the SSS value of libraries. Section 4 evaluates and predicts the SSS value of libraries. Section 5 analyzes the functional value of the SSM of libraries. Through experiments, the authors proved the effectiveness of the proposed prediction model and quantified the values of the SSS functions of libraries.

This paper improves and enriches the social service model (SSM) and value evaluation method of traditional libraries. On the one hand, the utilization of university library resources was visually displayed in a digital way. On the other hand, targeted opinions and suggestions were presented for optimizing the resource allocation of libraries. Suffice it to say that this paper is a meaningful attempt to maximize the utilization value of university library resources.

\section{SSS of Libraries}

In the context of sharing economy, the key lies in exerting the sharing service effects of the SSS system for libraries, which integrates rich technology, information, and human resources. The SSS process of libraries covers the entire procedure of knowledge sharing and spans across every link of SSS, namely, knowledge identification, fusion, extraction, and application. Combined with the planned SSS strategy of libraries, the traditional borrowing model should be transformed into SSS through step-by-step construction and implementation. Therefore, this paper proposes the framework of SSS system for library (Figure 1), which encompasses four core elements, namely, social sharing resources, social sharing technologies, social sharing processes, and social sharing strategies.

Traditionally, library information service centers around information resources. The rich information resources give libraries the dominance in information service. However, the information resource-centred information service model

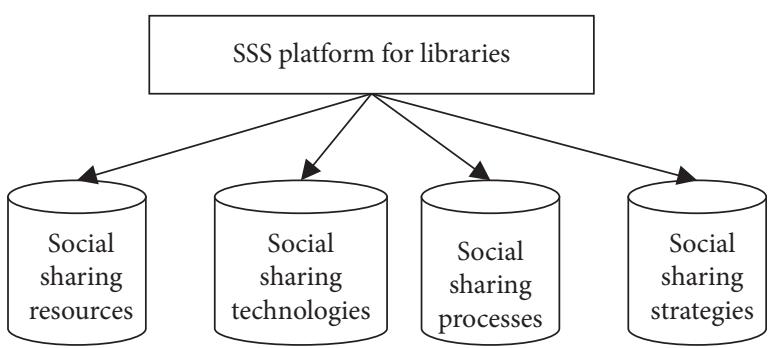

Figure 1: Framework of the SSS system for libraries.

is breaking down, as changes have taken place in the carrier form and communication method of literature information. Libraries have a wide range of physical books and e-books. The different types of resources differ vastly in attributes. To facilitate the SSS of libraries, it is necessary to establish a sharing mechanism for each kind of entities and electronic resources. During the construction of social sharing resources for libraries, the social service means should be diversified to offer varied service items and contents. Figure 2 illustrates the structure of knowledge sharing service chain, which, to some degree, reflects the construction procedure of the social sharing resources for libraries following the law of knowledge transform. It can be inferred that the orderly management of knowledge flow is a chained procedure of knowledge sharing service, including knowledge identification, knowledge extraction, knowledge fusion, knowledge visualization, knowledge storage, and knowledge sharing.

Specifically, the SSS procedure of libraries consists of four stages, namely, survey on sharing demand, formation of knowledge chain, implementation of knowledge sharing, and application of mature knowledge (Figure 3).

As shown in Figure 3, the survey on sharing demand aims to identify the demand of sharing subjects for knowledge innovation. Each sharing subject needs to pinpoint its knowledge gaps through evaluation of its professional domain knowledge structure, required entities, and electronic resources. Then, the sharing subjects should form the willingness to share knowledge and determine their sharing strategies, demand, and opportunities.

The formation of knowledge chain is the preparatory stage of actual knowledge sharing. According to the goal of knowledge innovation, the optimal knowledge sharing subjects are selected, driven by sharing demand, the necessary physical or electronic resources are defined, and the sharing platform and environment are clarified.

The implementation of knowledge sharing refers to the sharing, transfer, and innovation of knowledge. Knowledge is accumulated, processed, transformed, and innovated in the production space, fusion space, dialog space, and practice space provided by libraries.

The application of mature knowledge refers to the verification and reapplication of knowledge after innovation. Based on the evaluated effects, sharing degree, and value of knowledge sharing, the influencing factors of the sharing process can be corrected and adjusted, such as to ensure the smoothness of the next round of knowledge sharing. 


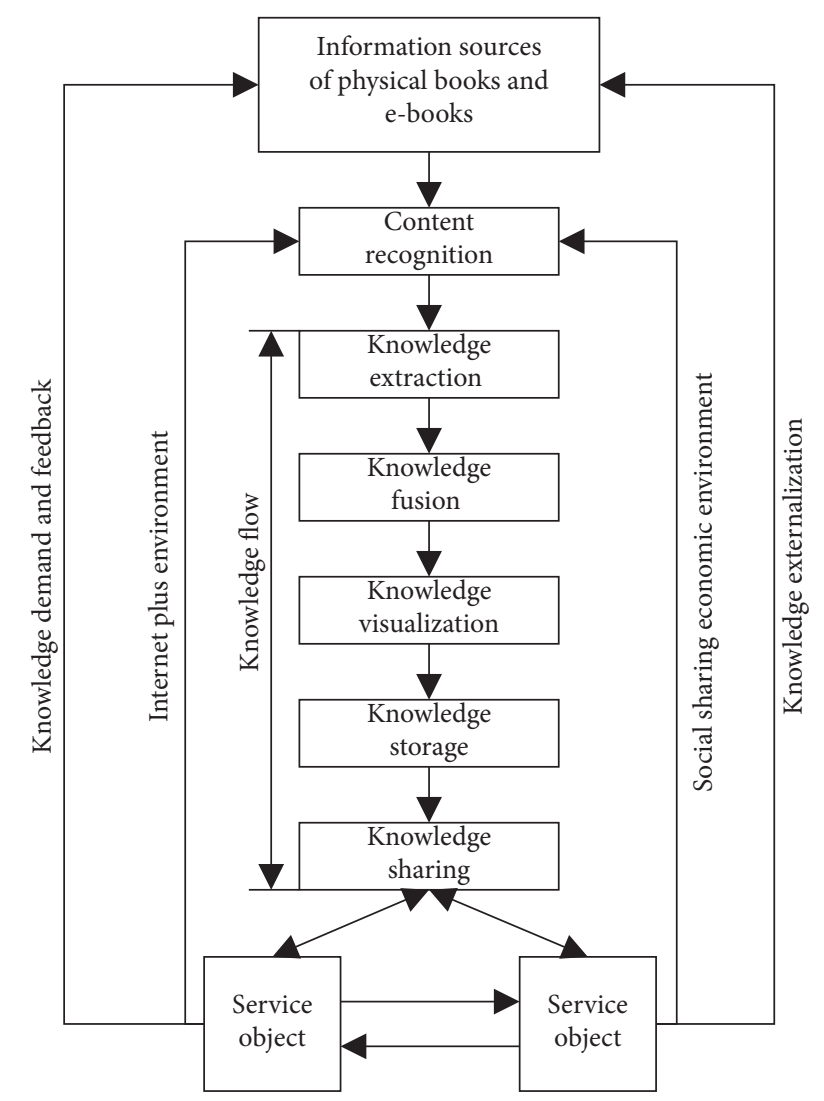

FIGURE 2: Structure of knowledge sharing service chain.

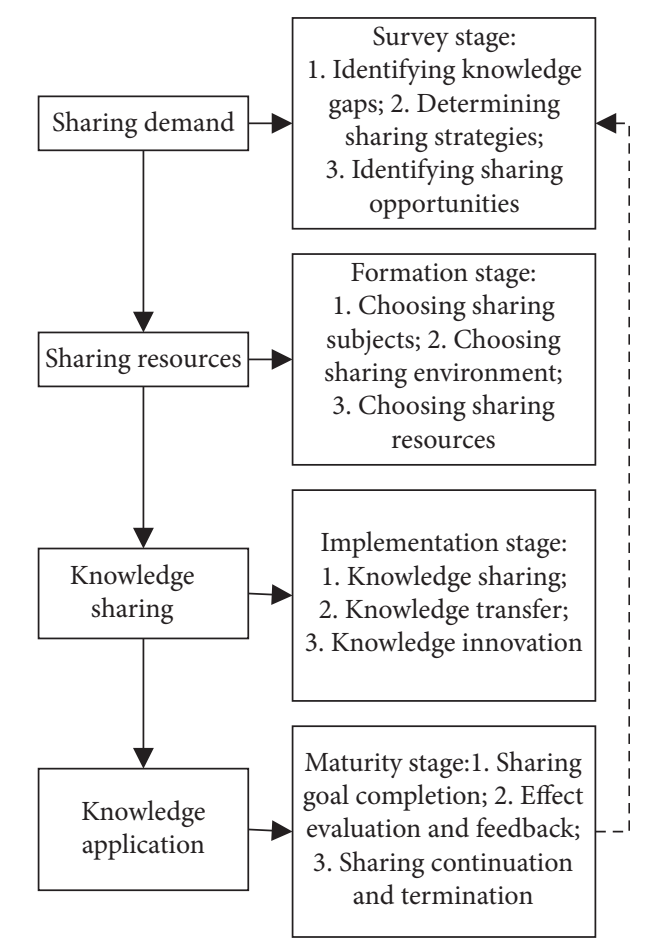

Figure 3: Procedure of knowledge sharing service.

To survive the impact of sharing economy, libraries must adapt quickly to the trend of information sharing services. The proposal of library SSS is essentially an adaptation to the changes in the internal and external environment of libraries. The framework of library SSS consists of a base layer, a physical layer, and a virtual layer (Figure 4).

To survive the sharing economy, libraries must quickly integrate into the wave of information sharing services. The proposal of the library SSS is actually an adaptive change to the changes in the internal and external environment of the library. Its structural framework specifically includes the basic layer, the physical layer, and the virtual layer in Figure 4.

In knowledge sharing, there are significant correlations between dimensions like library finance, social service targets, service business flow, and service development and innovation. The library SSS covers all the aspects of SSS, including sharing subjects, sharing resources, and sharing environment. In addition, the library SSS model must be designed according to how knowledge moves through the entire knowledge sharing flow from knowledge generation to knowledge innovation. In the library SSS, the regular flows of the service targets in daily learning and scientific research are fully integrated to share the physical and electronic resources of libraries and other open resources of colleges and institutions. In this way, the service targets are provided a series of services, such as the bases of resource retrieval, knowledge analysis, knowledge storage, and knowledge application. The purpose is to ensure that each service target, learning team, or research organization can smoothly acquire physical and electronic resources, and other services, fulfilling any of their knowledge demand.

\section{EIS Construction}

Based on the proposed library SSS model, this paper sets up an EIS for library SSS value from four dimensions: library finance, social service targets, service business flow, and service development and innovation. The EIS was constructed under the principle of scientificalness, objectiveness, and operability and in reference to the principles and standards of other SSS value EISs.

The four primary indices include the following.

$\mathrm{SV}=\left\{\mathrm{SV}_{1}, \mathrm{SV}_{2}, \mathrm{SV}_{3}, \mathrm{SV}_{4}\right\}=\{$ library finance, social service targets, service business flow, service development and innovation\}.

The secondary indices are as follows:

$\mathrm{SV}_{1}=\left\{\mathrm{SV}_{11}, \mathrm{SV}_{12}, \mathrm{SV}_{13}\right\}=\{$ profit function, resource utilization function, service guarantee function

$\mathrm{SV}_{2}=\left\{\mathrm{SV}_{21}, \mathrm{SV}_{22}, \mathrm{SV}_{23}\right\}=\{$ social service attributes, social image and reputation, service target demand

$\mathrm{SV}_{3}=\left\{\mathrm{SV}_{31}, \mathrm{SV}_{32}, \mathrm{SV}_{33}\right\}=\{$ social service quality, social service efficiency, social service tracking\}

$\mathrm{SV}_{4}=\left\{\mathrm{SV}_{41}, \mathrm{SV}_{42}\right\}=\{$ social service quality, social service incentives\}

The secondary indices were further broken down to the following tertiary indices:

$\mathrm{SV}_{11}=\left\{\mathrm{SV}_{111}, \mathrm{SV}_{112}\right\}=$ government funds on books, per-capita book funds under sharing economy, profits 


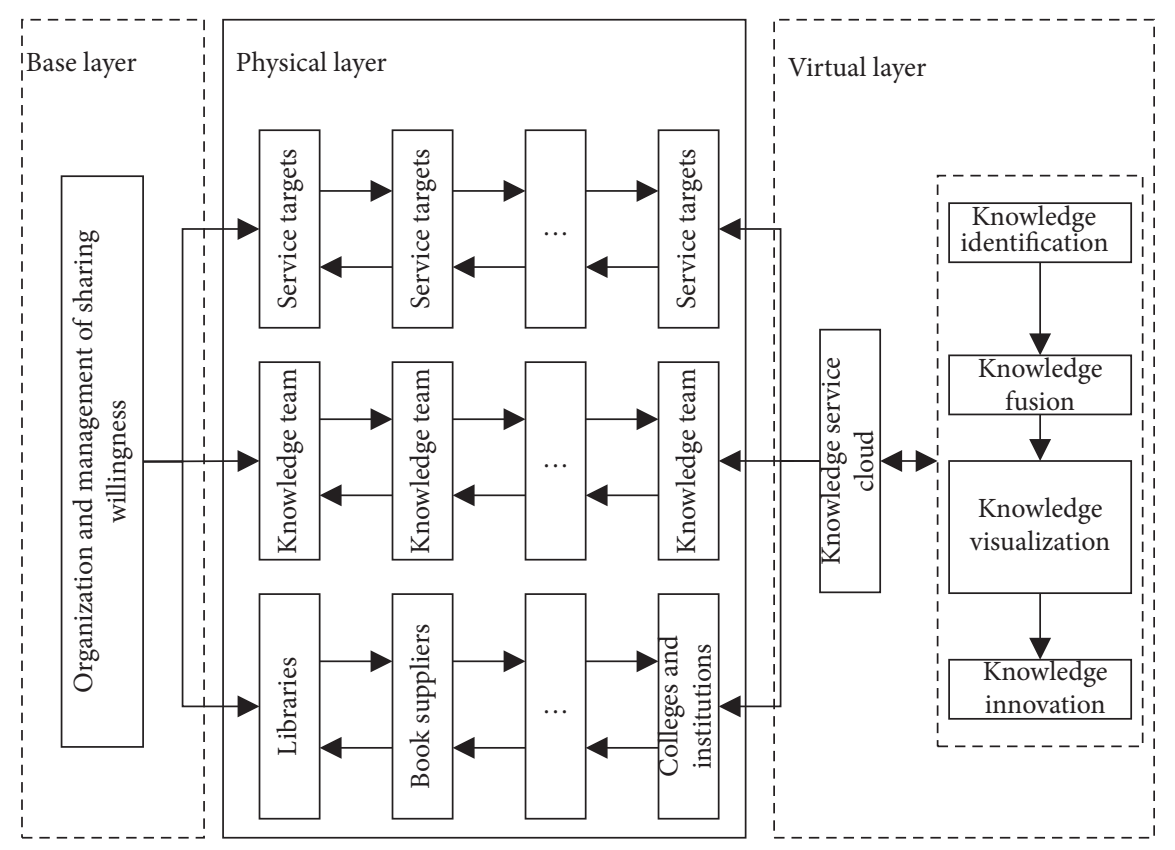

FIGURE 4: SSS of libraries.

from cultural and creative products or other consumption models\}

$\mathrm{SV}_{12}=\left\{\mathrm{SV}_{121}, \mathrm{SV}_{122}\right\}=\{$ utilization rate of public places, utilization rate of public facilities, utilization rate of audio-visual equipment, book circulation rate $\}$

$\mathrm{SV}_{13}=\left\{\mathrm{SV}_{131}, \mathrm{SV}_{132}, \mathrm{SV}_{133}\right\}=\{$ building area, book volume, characteristic literature volume $\}$

$\mathrm{SV}_{21}=\left\{\mathrm{SV}_{211}, \mathrm{SV}_{212}, \mathrm{SV}_{213}, \mathrm{SV}_{214}, \mathrm{SV}_{215}, \mathrm{SV}_{216}\right\}=$ \{opening time, open reading rate, interlibrary loan and document delivery, electronic resource coverage, daily service time\}

$\mathrm{SV}_{22}=\left\{\mathrm{SV}_{221}, \mathrm{SV}_{222}\right\}=\{$ daily shared information, daily served persons\}

$\mathrm{SV}_{23}=\left\{\mathrm{SV}_{231}, \mathrm{SV}_{232}, \mathrm{SV}_{233}, \mathrm{SV}_{234}\right\}=\{$ discipline coverage rate, personal borrowing quantity limit, duplicate checking service rate, e-book provision rate\}

$\mathrm{SV}_{31}=\left\{\mathrm{SV}_{311}, \mathrm{SV}_{312}, \mathrm{SV}_{313}\right\}=\{$ book integrity rate, electronic resource database recall rate, book missing rate

$\mathrm{SV}_{32}=\left\{\mathrm{SV}_{321}, \mathrm{SV}_{322}, \mathrm{SV}_{323}\right\}=\{$ book borrowing cycle, per-capita download frequency of electronic resources, per-capita frequency of consultation service\}

$\mathrm{SV}_{33}=\left\{\mathrm{SV}_{331}, \mathrm{SV}_{332}\right\}=\{$ service target satisfaction rate, satisfaction rate of book borrowing or electronic resource demand, venue and environment satisfaction rate

$\mathrm{SV}_{41}=\left\{\mathrm{SV}_{411}, \mathrm{SV}_{412}\right\}=\{$ proportion of student users, proportion of teaching and research personnel, proportion of users with medium and senior professional titles\}
$\mathrm{SV}_{42}=\left\{\mathrm{SV}_{421}\right\}=\{$ on-the-job training hours for library practitioners $\}$

\section{Value Evaluation and Prediction}

4.1. Basic Prediction Model. This paper establishes a fuzzy neural network (FNN), which encompasses such four layers as an input layer, a membership function layer, a rule layer, and an output layer (Figure 5).

Suppose the input layer of the FNN has a total of $m$ nodes. Then, the evaluation indices, as input variables, can be described as $A=\left[a_{1}, a_{2}, \ldots, a_{m}\right]^{T}$. The output $o$ of the $i$-th node can be calculated by

$$
o_{i}=a_{i}, \quad i=1,2, \ldots, m .
$$

The membership function layer contains $m \times e$ nodes, which represent Gaussian membership functions. Let $\lambda_{i j}$ be the value of the $j$-th membership function of $a_{i}$ and $h_{i j}$ and $\varepsilon_{i j}$ be the corresponding center and width, respectively. Then, the FNN output can be described as

$$
\lambda_{i j}\left(a_{i}\right)=e^{-\left(a_{i}-h_{i j}\right)^{2} / \varepsilon_{i j}^{2}}, \quad i=1,2, \ldots, m ; j=1,2, \ldots, e .
$$

The rule layer has a total of $e$ nodes representing the antecedents of the fuzzy rules. The output of the $j$-th rule node can be calculated by

$$
\Gamma_{j}(a)=\prod_{i=1}^{m} \lambda_{i j}\left(a_{i}\right)=e^{-\sum_{i=1}^{m}\left(a_{i}-h_{i j}\right)^{2} / \varepsilon_{i j}^{2}}, \quad j=1,2, \ldots, e .
$$




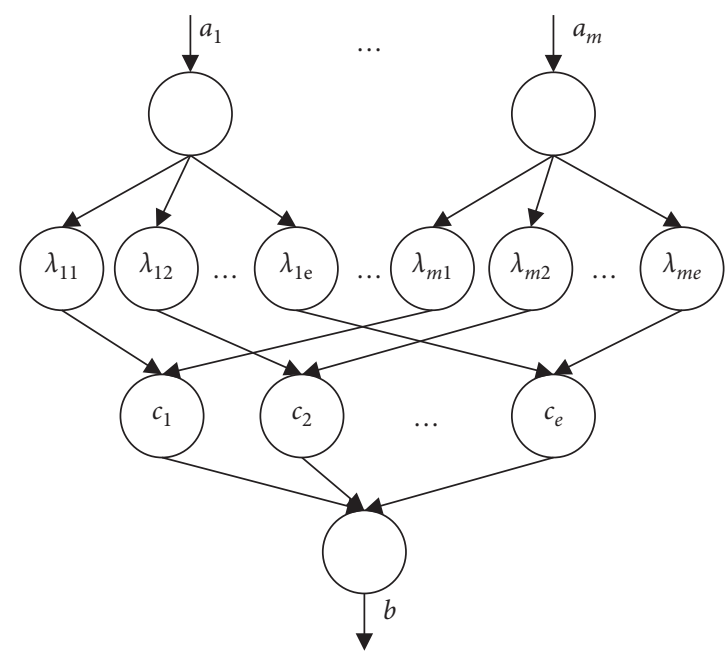

FIGURE 5: Structure of the proposed basic prediction neural network.

Let $c=\left[c_{1}, c_{2}, \ldots, c_{m}\right]^{T}$ be the normalized output vector of the rule layer. Then,

$$
c_{j}(x)=\frac{\Gamma_{j}(a)}{\sum_{l=1}^{e} \Gamma_{l}(a)}=\frac{e^{-\sum_{i=1}^{m}\left(a_{i}-h_{i j}\right)^{2} / \varepsilon_{i j}^{2}}}{\sum_{l=1}^{e} e^{-\sum_{i=1}^{m}\left(a_{i}-h_{i l}\right)^{2} / \varepsilon_{i l}^{2}}}, \quad j=1,2, \ldots, e .
$$

Let $\omega j$ be the result of the $j$-th rule. Then, the output of the rule layer can be solved through weighted summation of the inputs of the output layer:

$$
b(a)=\sum_{j=1}^{e} \omega_{j} c_{j}=\frac{\sum_{j=1}^{e} \omega_{j} e^{-\sum_{i=1}^{m}\left(a_{i}-h_{i j}\right)^{2} / \varepsilon_{i j}^{2}}}{\sum_{l=1}^{e} e^{-\sum_{i=1}^{m}\left(a_{i}-h_{i l}\right)^{2} / \varepsilon_{i l}^{2}} .}
$$

Drawing on backpropagation neural network (BPNN), the FNN can realize one-step prediction by changing $a_{i}$ in formula (5) into $\mathrm{FO}(l)$ in formula (6), which represents the FNN output:

$$
b_{n}(l+1)=\sum_{j=1}^{e} \omega_{j} c_{j}=\frac{\sum_{j=1}^{e} \omega_{j} e^{-\sum_{i=1}^{m}\left(\mathrm{FO}(l)-h_{i j}\right)^{2} / \varepsilon_{i j}^{2}}}{\sum_{l=1}^{e} e^{-\sum_{i=1}^{m}\left(\mathrm{FO}(l)-h_{i l}\right)^{2} / \varepsilon_{i l}^{2}} .}
$$

The multistep prediction model can be described by

$b_{n}(l+t+1)=\sum_{j=1}^{e} \omega_{j} c_{j}=\frac{\sum_{j=1}^{e} \omega_{j} e^{-\sum_{i=1}^{m}\left(\mathrm{FO}(l+t)-h_{i j}\right)^{2} / \varepsilon_{i j}^{2}}}{\sum_{l=1}^{e} e^{-\sum_{i=1}^{m}\left(\mathrm{FO}(l+t)-h_{i l}\right)^{2} / \varepsilon_{i l}^{2}}}$

4.2. Design of the Improved Network Model. To speed up network convergence, the structure and parameters of the proposed neural network should be recognized and estimated. The risk assessment filter (RAF) algorithm, which is based on fuzzy Gaussian kernel clustering, was adopted to automatically divide the space of the input samples of the evaluation indices. In this way, the initial fuzzy rules were extracted, and the SSS value of the target library was predicted. In the RAF algorithm, the fuzzy rules are automatically divided by the following standard: the mean variance of evaluated levels for SSM value. Suppose the evaluated levels belong to $e$ clusters. The results were divided into five levels: excellent, good, neutral, qualified, and poor. Let $\left(t_{\mathrm{AV}-j}\right)^{2}$ be the mean variance of the clusters corresponding to the $j$-th evaluated level. Then, the evaluated level with the largest mean variance can be identified by

$$
\mathrm{AL}=\arg \max _{1 \leq j \leq w}\left(t_{\mathrm{AV}-j}\right)^{2},
$$

where $\left(t_{\mathrm{AV}-j}\right)^{2}$ is the sum of the variances of the index samples:

$$
\left(t_{\mathrm{AV}-j}\right)^{2}=\sum_{i=1} t_{i j}^{2}
$$

Let $a \in u_{j}$ be the membership of index sample a to the $j$-th evaluated level and $u_{i j}$ and $S N_{j}$ be the $i$-th dimensional center and the number of samples corresponding to the $j$-th evaluated level, respectively. Then, the corresponding variance $t_{i j}$ can be calculated by

$$
s_{i j}^{2}=\frac{1}{p_{j}} \sum_{x \in v_{j}}\left(x_{i j}-v_{i j}\right)^{2} t_{i j}^{2}=\frac{1}{\mathrm{SN}_{j}} \sum_{x \in u_{j}}\left(a_{i j}-u_{i j}\right)^{2} .
$$


If $s_{\mathrm{AV}-\mathrm{AL}}{ }^{2}$ is greater than the preset threshold $S^{*}$, then the $i$-th cluster centering on $u_{\mathrm{AV}-\mathrm{AL}}=\left(u_{\mathrm{AL} 1}, u_{\mathrm{AL} 2}, \ldots, u_{\mathrm{AL} m}\right)$ will be divided into two new clusters, respectively, centering on $u_{\mathrm{AV}-\mathrm{AL}}+\beta$ and $u_{\mathrm{AV}-\mathrm{AL}}-\beta$, where $\beta$ is a small positive constant.

After the division of fuzzy rules, the $e$ clusters were calculated iteratively by the fuzzy $c$-means (FCM) clustering algorithm until $s_{\mathrm{AV}-\mathrm{AL}}{ }^{2}$ falls below the preset threshold $S^{*}$.

By minimizing the second-order objective function, the FCM clustering algorithm calculates the membership of each index sample to the cluster center corresponding to each evaluated level. In this way, the evaluation index dataset was automatically classified.

Let $A=\left\{a_{1}, a_{2}, \ldots, a_{K}\right\}$ be the network training set, $u=$ $\left\{u_{1}, u_{2}, \ldots, u_{D}\right\}$ be cluster centers, $K$ be the number of index samples, $D$ be the number of cluster centers, $\mathrm{OF}_{n}$ be the objective function for library SSM value, $n$ be the fuzzy index; $\lambda_{k d}$ be the membership of the $k$-th index sample to the $d$-th cluster center, and $\mathrm{F}$ be the feature mapping function. Then, the objective function of FCM clustering can be defined by

$$
\begin{array}{r}
\mathrm{OF}_{n}=\sum_{d=1}^{D} \sum_{k=1}^{K} \lambda_{k d}^{n}\left\|F\left(a_{k}\right)-F\left(u_{d}\right)\right\|^{2}, \\
\text { s.t. } \sum_{d=1}^{D} \lambda_{k d}=1, \quad 0 \leq \lambda_{k d} \leq 1 .
\end{array}
$$

Based on the rules for kernel method transform, the feature mapping function between indices and cluster centers can be constructed as

$$
\begin{aligned}
\left\|F\left(a_{k}\right)-F\left(u_{d}\right)\right\|^{2} & =\left(F\left(a_{k}\right)-F\left(u_{d}\right)\right)^{T}\left(F\left(a_{k}\right)-F\left(u_{d}\right)\right) \\
& =F\left(a_{k}\right)^{T} F\left(a_{k}\right)-F\left(a_{k}\right)^{T} F\left(u_{d}\right)-F\left(u_{d}\right)^{T} F\left(a_{k}\right)+F\left(u_{d}\right)^{T} F\left(u_{d}\right) \\
& =\mathrm{GN}\left(a_{k}, a_{k}\right)+\mathrm{GN}\left(u_{d}, u_{d}\right)-2 \mathrm{GN}\left(a_{k}, u_{d}\right) .
\end{aligned}
$$

Let $\delta$ be the width of cluster center. Then, the Gaussian function GN in formula (12) can be defined as

$$
\begin{array}{r}
K(x, v)=\exp \left[-\frac{\|x-v\|^{2}}{b^{2}}\right], \\
\operatorname{GN}(a, u)=e^{-\|a-u\|^{2} / \delta^{2}} .
\end{array}
$$

Since $\operatorname{GN}(a, a)=1$, the objective function (11) can be rewritten as

$$
\mathrm{OF}_{n}=2 \sum_{d=1}^{D} \sum_{k=1}^{K} \lambda_{k d}^{n}\left(1-\mathrm{GN}\left(a_{k}, u_{d}\right)\right)
$$

The optimal solution of (14) can be obtained by updating $u_{d}$ and $\lambda_{k d}$ :

$$
\begin{aligned}
u_{d} & =\frac{\sum_{k=1}^{K} \lambda_{k d}^{n} \mathrm{GN}\left(a_{k}, u_{d}\right) a_{k}}{\sum_{\mathrm{MV}=1}^{\mathrm{MV}} \lambda_{k d}^{n} \mathrm{GN}\left(a_{k}, u_{d}\right)} \\
\lambda_{k d} & =\frac{\left(1-\mathrm{GN}\left(a_{k}, u_{d}\right)\right)^{-1 /(n-1)}}{\sum_{d=1}^{D}\left(1-\mathrm{GN}\left(a_{k}, u_{d}\right)\right)^{-1 /(n-1)}} .
\end{aligned}
$$

Moreover, the nonexact Lagrangian multiplier method was introduced to the proposed prediction model to enhance the convergence speed and generalization ability. Let $\Psi(\tau)=[\omega(\tau), o(\tau), \varepsilon(\tau)]$ be the vector of network parameters, Jaco be the Jacobian matrix, $v(\tau)$ be the learning rate of the network, and $\varphi(\tau)=\left[\varphi_{1}(\tau), \varphi_{2}(\tau), \ldots, \varphi_{q}(\tau)\right]^{T}$ be the error vector. Based on the traditional Levenberg-Marquardt (LM) algorithm, network parameters can be updated by
$\Psi(\tau+1)=\Psi(\tau)-\left(\operatorname{Jaco}(\tau)^{T} \operatorname{Jaco}(\tau)+v(\tau) I\right)^{-1} \operatorname{Jaco}(\tau)^{T} \mathrm{WC}(\tau)$.

The error of the $q$-th sample can be defined as

$$
\phi^{q}(\tau)=b_{d}^{q}(\tau)-b^{q}(\tau), \quad q=1,2, \ldots, K .
$$

The Jacobian matrix can be calculated by

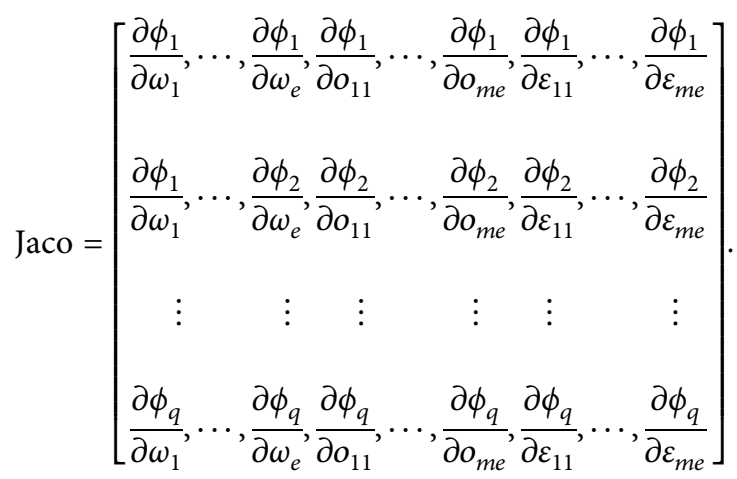

Formula (19) shows that the number of rows and columns of the Jacobina matrix represent the number of index samples and the number of network parameters, respectively. Therefore, the computation overhead and storage volume will increase prominently with the growing number of training samples. This problem can be solved effectively by introducing the nonexact Lagrangian multiplier method. Let $\mathrm{GH}(\tau)$ be the quasi-Hessian matrix and $\mathrm{GV}(\tau)$ be the gradient vector. Then, parameter vector $\Psi(\tau)$ can be updated by

$$
\Psi(\tau+1)=\Psi(\tau)-(\mathrm{GH}(\tau)+v(\tau) I)^{-1} \mathrm{GV}(\tau) .
$$


Suppose $\alpha$ is a constant in the range of $[0,1]$. Then, the adaptive learning rate $v(\tau)$ can be calculated by

$$
v(\tau)=\alpha\|\phi(\tau)\|+(1-\alpha)\|\mathrm{GV}(\tau)\| .
$$

$\mathrm{GH}(\tau)$ and $\mathrm{GV}(\tau)$ can be, respectively, calculated by

$$
\begin{aligned}
& \mathrm{GH}(\tau)=\sum_{q=1}^{K} \mathrm{GH}_{q}(\tau), \\
& \mathrm{GV}(\tau)=\sum_{q=1}^{K} \omega_{q}(\tau),
\end{aligned}
$$

where the submatrix $\mathrm{GH}_{q}(\tau)$ can be defined by

$$
\begin{aligned}
& \Psi(t)=j_{p}^{T} j_{p}(t), \\
& \psi(\tau)=\mathrm{KB}_{q}^{T} \mathrm{~KB}_{q}(\tau) .
\end{aligned}
$$

Let $\operatorname{Jaco}_{q}(\tau)$ be the row vector of the Jacobian matrix. Then, the subvector $\omega_{q}(\tau)$ can be defined by

$$
\omega_{q}(\tau)=\operatorname{Jaco}_{q}^{T} \phi_{q}(\tau) .
$$

Then, the elements about $\omega_{i j}(\tau)$ in the row vector can be calculated by

$$
\frac{\partial \phi_{q}(\tau)}{\partial \omega_{j}(\tau)}=\frac{\partial \phi_{q}(\tau)}{\partial b_{q}(\tau)} \frac{\partial b_{q}(\tau)}{\partial \omega_{j}(\tau)}=-L_{j}(\tau) .
$$

The elements about $o_{i j}(\tau)$ in the row vector can be calculated by

$$
\begin{aligned}
\frac{\partial \phi_{q}(\tau)}{\partial o_{i j}(\tau)} & =\frac{\partial \phi_{q}(\tau)}{\partial b_{q}(\tau)} \frac{\partial b_{q}(\tau)}{\partial L_{j}(\tau)} \frac{\partial L_{j}(\tau)}{\partial \xi_{j}(\tau)} \frac{\partial \xi_{j}(\tau)}{\partial \lambda_{i j}(\tau)} \frac{\partial \lambda_{i j}(\tau)}{\partial o_{i j}(\tau)} \\
& =-\omega_{j}(t) \frac{\sum_{r \neq j}^{R} \xi_{r}(t)}{\left(\sum_{r=1}^{R} \xi_{r}(t)\right)^{2}} \prod_{r \neq j}^{m} \lambda_{r j}(t) \frac{\partial \lambda_{i j}(t)}{\partial o_{i j}(t)}
\end{aligned}
$$

The elements about $\varepsilon_{i j}(\tau)$ in the row vector can be calculated by

$$
\begin{aligned}
\frac{\partial \phi_{q}(\tau)}{\partial \varepsilon_{i j}(\tau)} & =\frac{\partial \phi_{q}(\tau)}{\partial b_{q}(\tau)} \frac{\partial b_{q}(\tau)}{\partial L_{j}(\tau)} \frac{\partial L_{j}(\tau)}{\partial \xi_{j}(\tau)} \frac{\partial \xi_{j}(\tau)}{\partial \lambda_{i j}(\tau)} \frac{\partial \lambda_{i j}(\tau)}{\partial \varepsilon_{i j}(\tau)} \\
& =-\omega_{j}(\tau) \frac{\sum_{r \neq j}^{R} \xi_{r}(\tau)}{\left(\sum_{r=1}^{R} \xi_{r}(\tau)\right)^{2}} \prod_{r \neq j}^{m} \lambda_{r j}(\tau) \frac{\partial \lambda_{i j}(\tau)}{\partial \varepsilon_{i j}(\tau)},
\end{aligned}
$$

where the partial derivatives of membership relative to $o_{i j}(\tau)$ and $\varepsilon_{i j}(\tau)$ can be calculated by

$$
\begin{gathered}
\frac{\partial \lambda_{i j}(\tau)}{\partial o_{i j}(t)}=\frac{2\left(a_{i}(\tau)-o_{i j}(\tau)\right) e^{\left(-\left(a_{i}(\tau)-\mathrm{AH}_{i j}(\tau)\right)^{2} / \varepsilon_{i j}^{2}(t)\right.}}{\varepsilon_{i j}^{2}(t)}, \\
\frac{\partial \lambda_{i j}(\tau)}{\partial \varepsilon_{i j}(\tau)}=\frac{2\left(a_{i}(\tau)-o_{i j}(\tau)\right)^{2} e^{\left(-\left(a_{i}(\tau)-\mathrm{AH}_{i j}(\tau)\right)^{2} / \varepsilon_{i j}^{2}(t)\right.}}{\varepsilon_{i j}^{3}(\tau)} .
\end{gathered}
$$

\section{Functional Value Analysis}

To further analyze the SSS functional values of libraries, the SSM values evaluated by the previously established model under the sharing economy were summed up and compared with the human, financial, and material resources invested to realize the ideal values, producing the functional cost ratio of resource utilization by the SSM of each library, that is, the functional value of SSM for each library. The value management formula can be described by

$$
(\text { value })=\frac{(\text { function })}{(\text { cost })} \text {. }
$$

Then, the SSM value of a library JXW equals the ratio of SSM functions (JXG) to social service cost (JXK) of the library:

$$
\mathrm{JXW}=\frac{\mathrm{JXG}}{\mathrm{JXK}}
$$

During the SSM value management of libraries, it is difficult to unify the units of SSM functions and input costs, the units of the dimensions of SSM functions, or the units of the dimensions of input costs. To solve the problem, this paper introduces the relative coefficient ratio to compute the SSM value of libraries. Let $\eta$ be the SSM functional coefficient and $G_{i}$ be the functional value of library SSM in the $i$-th year. Then, the total SSM functional value of a library can be described by $\Sigma^{N}{ }_{i=1} G_{i}$. Then,

$$
\eta=\frac{G_{i}}{\sum_{i=1}^{N} G_{i}} .
$$

Formula (32) shows that $\eta$ is the ratio of the SSM functional value in a year to the total functional value in the research period. Let $\gamma$ be the cost coefficient of social services of a library, $K_{i}$ be the social service cost in the $i$-th year, and $\Sigma^{N}{ }_{i=1} K_{i}$ be the total social service cost of the library in the research period. Then,

$$
\gamma=\frac{K_{i}}{\sum_{i=1}^{N} K_{i}}
$$

Hence, $\gamma$ is the input cost of the library in a year to the total input cost in the research period. Then, the SSM value coefficient of the library can be described as

$$
\rho=\frac{\eta}{\gamma}
$$

\section{Experiments and Result Analysis}

Figure 6 compares the training error curves of BPNN, RBFN, and our model through 600 iterations. When all network parameters were the same, the training error fluctuated slightly and tended to be stable after 500 iterations. BPNN and RBFN had basically the same root mean square error (RMSE), convergence speed, and convergence accuracy. Our model surpassed them in convergence speed and accuracy. 


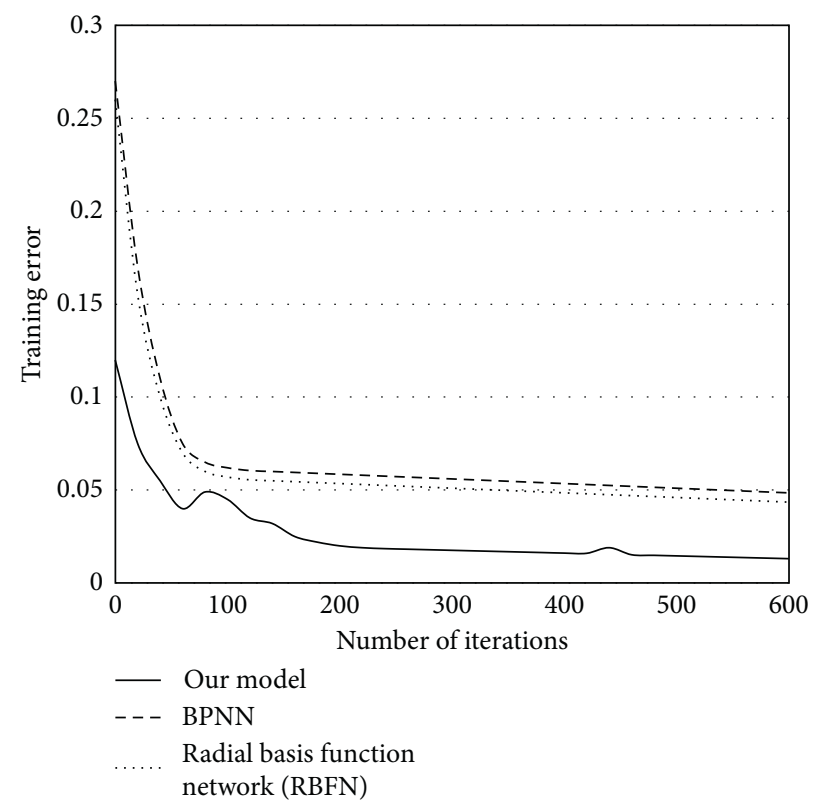

Figure 6: Training error curves.

This proves the effectiveness of the proposed FNN in predicting the value of library SSM.

To further verify the prediction accuracy of our FNN, the said three models were tested on the same index samples. Their prediction outputs were compared in detail. Figure 7 presents the prediction errors of the three models between the $1,000^{\text {th }}$ iteration and $1,060^{\text {th }}$ iteration. Our prediction model minimized the difference between the predicted SSM value and the expected SSM value, among the three models.

To realize the ideal functional value, each library needs to pay a labor cost, that is, the total salary required by the state, including the basic wage and allowances. Table 1 shows the salary payment by libraries in China to workers with different professional titles.

The financial cost of a library mainly refers to the investment in the projects under construction. It can be incurred by venue construction/expansion, the purchase of physical books, the addition of borrowing and retrieval equipment, the utilization of electronic resource databases, and operations like administration and businesses. Table 2 shows the cost incurred by the purchase of physical books, the utilization of electronic resource databases, and operations of Chinese libraries in 2015-2020.

The material cost of a library mainly refers to the physical form of the existing fixed assets, which covers venue scale, investment of existing equipment, total amount of physical books, total amount of electronic resource databases, and so on. Table 3 shows the estimated cost of library material resources in China during 2015-2020.

According to the analysis results on the SSS functional value, the SSS functions were optimal at $\rho=1$, indicating that the model needs no adjustment or improvement. In fact, $\rho$ is acceptable as long as it falls between 1.15 and 0.85 . Table 4 shows the functional value of library SSS increased year by year; that is, the human, financial, and material invested by

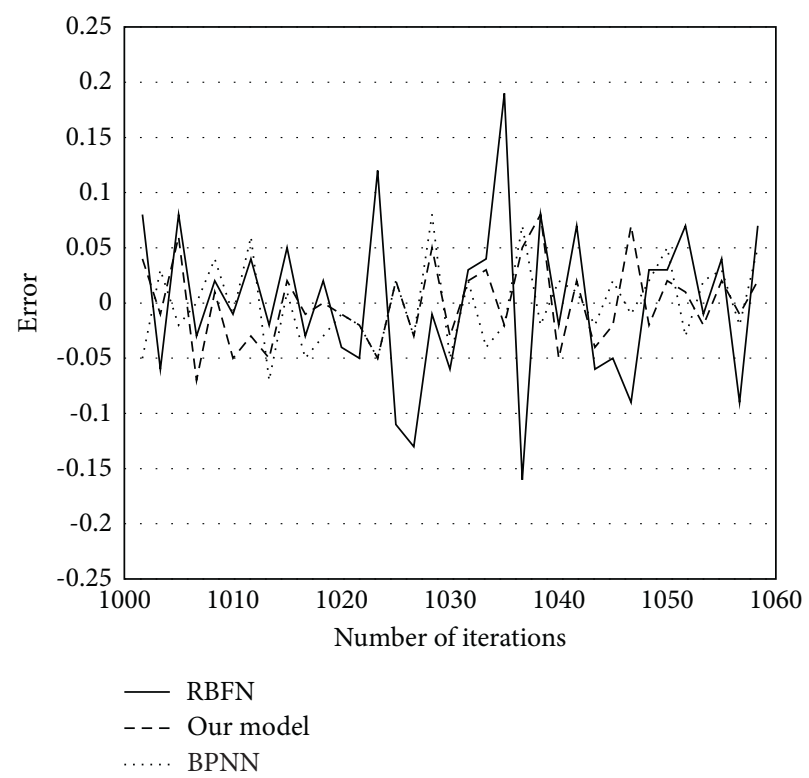

Figure 7: Prediction errors of different models.

TABLE 1: Labor cost of libraries in 2015-2020.

\begin{tabular}{cccc}
\hline Year & \multicolumn{3}{c}{ Title } \\
& Senior & Medium & Below medium \\
\hline 2015 & 11 & 35 & 59 \\
2016 & 16 & 32 & 52 \\
2017 & 17 & 31 & 45 \\
2018 & 19 & 29 & 42 \\
2019 & 20 & 25 & 41 \\
2020 & 22 & 21 & 39 \\
\hline
\end{tabular}

libraries are effective. Through the six years, the $\gamma$ value did not change much $(0.283,0.267,0.378,0.297,0.316$, and 0.429 ), suggesting that the annual income of libraries only 
TABle 2: Financial cost of libraries in 2015-2020.

\begin{tabular}{cccc}
\hline Year & & \multicolumn{2}{c}{$\begin{array}{c}\text { Item } \\
\text { Otilization of electronic resource databases }\end{array}$} \\
\hline 2015 & Purchase of physical books & 365.2 & 15 \\
2016 & 297.6 & 377.5 & 17 \\
2017 & 312.5 & 396.1 & 22 \\
2018 & 335.2 & 402.3 & 24 \\
2019 & 349.4 & 415.9 & 26 \\
2020 & 358.1 & 428.4 & 29 \\
\hline
\end{tabular}

TABLE 3: Material cost of libraries in 2015-2020.

\begin{tabular}{ccccc}
\hline Year & & & Item & \\
& Equipment investment & Venue scale & Total amount of physical books & Total amount of electronic resource databases \\
\hline 2015 & 31 & 41,583 & 201.5 & 68 \\
2016 & 42 & 40,532 & 202.1 & 72 \\
2017 & 45 & 40,532 & 203.9 & 77 \\
2018 & 46 & 40,532 & 208.3 & 80 \\
2019 & 50 & 40,612 & 214.5 & 86 \\
2020 & 52 & 40,612 & 221.7 & 94 \\
\hline
\end{tabular}

TABLE 4: Evaluated SSS values of libraries in 2015-2020.

\begin{tabular}{ccccccc}
\hline & \multicolumn{4}{c}{ Item } \\
Year & \multicolumn{2}{c}{ Service function } & \multicolumn{2}{c}{ Service cost } & \multicolumn{2}{c}{ Service value } \\
& $\eta$ & Ranking & $\gamma$ & Ranking & $\rho$ & Ranking \\
\hline 2015 & 0.297 & 6 & 0.283 & 5 & 0.832 & 6 \\
2016 & 0.332 & 5 & 0.267 & 6 & 0.951 & 5 \\
2017 & 0.396 & 4 & 0.378 & 2 & 1.254 & 3 \\
2018 & 0.428 & 3 & 0.297 & 4 & 1.108 & 4 \\
2019 & 0.475 & 2 & 0.316 & 3 & 1.443 & 2 \\
2020 & 0.542 & 1 & 0.429 & 1 & 1.672 & 1 \\
\hline
\end{tabular}

increased slightly. The growth of SSS value mainly comes from the rising functional value of SSM.

\section{Conclusions}

This paper explores the SSM and value evaluation of libraries under sharing economy. Firstly, the SSS of libraries was modeled as a system of a base layer, a physical layer, and a virtual layer, and an EIS was constructed for library SSS. Next, an improved FNN was established to evaluate and predict the SSS value of libraries, followed by an analysis on the functional value of library SSS. Through experiments, the training error of our model through 600 iterations was compared with that of BPNN and RBFN. The comparison confirms the effectiveness of our prediction model. Further, the SSS functional value was evaluated for libraries, leading to the conclusion that the growth of SSS value mainly comes from the rising functional value of SSM.

\section{Data Availability}

The data used to support the findings of this study are available from the corresponding author upon request.

\section{Conflicts of Interest}

The authors declare that they have no conflicts of interest regarding the publication of this paper.

\section{Acknowledgments}

This work was supported by the Scientific Research Cooperation Program of Human Resources and Social Security Department, Hebei Province, China, 2021 (Grant no. JRSHZ-2021-01065).

\section{References}

[1] S. Duan and Z. Wang, "Research on the service mode of the university library based on data mining," Scientific Programming, vol. 2021, Article ID 5564326, 9 pages, 2021.

[2] X. D. Du and W. Wang, "Discussion on university library service pattern in big data Era," in Proceedings of the 2017 IEEE 2nd International Conference on Big Data Analysis (ICBDA), pp. 597-600, Beijing, China, March 2017.

[3] D. P. Zuberbier, R. Agarwala, R. A. Chin, and M. M. Sanders, "Board\# 55: climbing to cruising altitude: promoting an academic library's 3D printing service," in Proceedings of the 2017 ASEE Annual Conference \& Exposition, Columbus, OH, USA, June 2017.

[4] D. Bangert and M. Frances, "PIDs to support discovery and citation: persistent identifier service design and delivery at UNSW library," in Proceedings of the 2017 ACM/IEEE Joint Conference on Digital Libraries (JCDL), pp. 1-2, Toronto, Canada, June 2017.

[5] L. K. Fai, L. W. Siew, and L. W. Hoe, "Analysis on the library service quality with analytic hierarchy process model," Journal of Physics: Conference Series, vol. 1706, no. 1, Article ID 012154, 2020.

[6] Y. Ariyanto, B. Harijanto, A. Setiawan, S. Adhisuwignjo, and E. Rohadi, "Integration of digital library server with Service 
Oriented Architecture (SOA) based on cloud computing using proxmox server," Journal of Physics: Conference Series, vol. 1402, no. 7, Article ID 077054, 2019.

[7] Y. Wang, H. He, and T. Liu, "Intelligent library information service terminal based on BDS and wireless communication," in Proceedings of the 2019 14th IEEE Conference on Industrial Electronics and Applications (ICIEA), pp. 955-959, Xi'an, China, June 2019.

[8] X. Kong, "Research on library knowledge service innovation in big data environment," in Proceedings of the 2020 International Conference on Big Data and Informatization Education (ICBDIE), pp. 64-68, Zhangjiajie, China, April 2020.

[9] Y. Chen, X. Liang, and J. Zhang, "Promotion of library service mode based on next-generation information technology," in Proceedings of the International Conference on Frontier Computing, pp. 1422-1426, Kitakyushu, Japan, July 2019.

[10] C.-H. Wu, Y.-H. Yuan, and S.-B. Tsai, "Using the DEMATEL model to expose core causal items of LibQUAL for improving library service quality: from the perspective of big data," Soft Computing, vol. 24, no. 8, pp. 5729-5739, 2020.

[11] C. M. La Fata and T. Lupo, "A combined fuzzy-SEM evaluation approach to identify the key drivers of the academic library service quality in the digital technology era: an empirical study," Journal of the Association for Information Science and Technology, vol. 68, no. 10, pp. 2425-2438, 2017.

[12] G. Retscher and A. Leb, "Development of a smartphone-based university library navigation and information service employing Wi-Fi location fingerprinting," Sensors, vol. 21, no. 2 , p. $432,2021$.

[13] S. S. Hilabi, S. H. Supangat, H. L. H. S. Warnars, H. Prabowo, and T. N. Mursitama, "Model technology service E-participation-voting (E-PV) for political communication between the council of regional representatives (DPRD) and the citizens using the framework information technology infrastructure library (ITIL V. 3) transition domain service," in Proceedings of the 2020 International Conference on ICT for Smart Society (ICISS), pp. 1-6, IEEE, Bandung, Indonesia, November 2020.

[14] A. R. Siregar and H. Dewiyana, "Mobile technology for expansion of service range medan public library," Journal of Physics: Conference Series, vol. 978, no. 1, Article ID 012052, 2018.

[15] D. Handoko and A. S. Girsang, "Service desk implementation with information technology infrastructure library framework (study case financial company)," Journal of Physics: Conference Series, vol. 1090, no. 1, Article ID 012059, 2018.

[16] Y. V. Singh, B. Kumar, and S. Chand, "A novel approach of requirements prioritization using logarithmic fuzzy trapezoidal AHP for enhancing academic library service," in Proceedings of the 2018 International Conference on Advances in Computing, Communication Control and Networking (ICACCCN), pp. 1164-1172, IEEE, Greater Noida, India, October 2018

[17] W. Liu, Q. Niu, C. Kong, and X. Zhou, "Service oriented crossplatform framework for 3D part library based on diversiform knowledge implantation," Computer-Aided Design and Applications, vol. 15, no. 6, pp. 872-879, 2018.

[18] R. Mehta, "Digital library service model for predictive analysis of user satisfaction based on multivariate fuzzy logic," Digital Library Perspectives, vol. 37, no. 1, pp. 36-53, 2021.

[19] G. Retscher and A. Leb, "Development of a navigation and information service for a university library," in Proceedings of the 2021 International Technical Meeting of The Institute of
Navigation, pp. 229-242, Long Beach, California, January 2021.

[20] I. Bikmullina and I. Valiullin, "Multi-service electronic library of scientific and technical articles," in Proceedings of the 2020 International Multi-Conference on Industrial Engineering and Modern Technologies (FarEastCon), pp. 1-5, Vladivostok, Russia, October 2020.

[21] N. Karna, D. Pratama, and M. Ramzani, "Self service system for library automation: case study at telkom university open library," in 2019 International Conference on Information and Communications Technology (ICOIACT), pp. 689-693, Yogyakarta, Indonesia, February 2019.

[22] Rismayeti and T. M. Sum, "Convenience environment in library and archives service: promotion activities evaluation in Pekanbaru," IOP Conference Series: Earth and Environmental Science, vol. 469, no. 1, Article ID 012071, 2020.

[23] P. Fithri, A. Adnan, and V. Syahmer, "Improving public library service quality in local city of Indonesia," MATEC Web of Conferences, vol. 154, Article ID 01047, 2018.

[24] D. Enjun, "Research on personalized service of library in colleges and universities based on data mining technology," Agro Food Industry Hi-Tech, vol. 28, no. 3, pp. 789-793, 2017.

[25] H. Herdiansyah, A. S. Utama, H. Hidayat, A. G. Z. Irawan, R. I. T. Muliawan, and D. M. Pratiwi, "Analysis of environmental friendly library based on the satisfaction and service quality: study at library "X"” IOP Conference Series: Earth and Environmental Science, vol. 88, no. 1, Article ID 012030, 2017.

[26] K. Kourai and K. Sannomiya, "Flexible service consolidation with nested virtualization and library operating systems," Software: Practice and Experience, vol. 50, no. 1, pp. 3-21, 2020.

[27] D. Soares-Silva, G. H. S. M. de Moraes, A. Cappellozza, and C. Morini, "Explaining library user loyalty through perceived service quality: what is wrong," Journal of the Association for Information Science and Technology, vol. 71, no. 8, pp. 954967, 2020. 